\title{
Movimentos pendulares e integração regional no leste fluminense
}

\author{
Hisrael Passarelli-Araujo* \\ Joseane de Souza**
}

\begin{abstract}
A pendularidade é uma importante medida para avaliar os processos de integração das cidades e a dinâmica populacional regional. Em 2015, o IBGE identificou a intensificação dos movimentos pendulares entre os municípios do leste fluminense, de Arraial do Cabo a São João da Barra, considerando-os aspectos relevantes da urbanização brasileira. Contudo, pouco se sabe sobre o peso da pendularidade entre esses municípios e o nível de interação que eles estabelecem com Macaé, principal destino dos pendulares na região. Esse trabalho analisa o grau de integração regional do vetor leste fluminense, a partir dos dados censitários de 2000 e 2010. A pendularidade por trabalho e/ou estudo observada em Macaé o coloca em posição de destaque entre os municípios selecionados. Afirmamos, portanto, que Macaé não é apenas uma cidade em movimento, mas também um município potencialmente integrador do mercado de trabalho das demais municipalidades da região. É em torno desse município que o tecido urbano regional tem se reorganizado. Esse estudo pode iluminar novas discussões sobre os processos recentes de urbanização no estado do Rio de Janeiro, sobretudo por se tratar de uma região demograficamente integrada, mas politicamente fragmentada.
\end{abstract}

Palavras-chave: Arranjos populacionais. Centralidade urbana. Rio de Janeiro.

\footnotetext{
* Universidade Federal de Minas Gerais (UFMG), Belo Horizonte-MG, Brasil (hisraelpassarelli@gmail.com; https://orcid. org/0000-0003-3534-8392).

** Universidade Estadual do Norte Fluminense Darcy Ribeiro (Uenf), Campos dos Goytacazes-RJ, Brasil (joseanedesouza. souza@gmail.com; https://orcid.org/0000-0002-3555-5423).
} 


\section{Introdução}

Os movimentos da população são uma das respostas demográficas mais importantes aos processos de crescimento e expansão das cidades nos últimos anos (CUNHA; FARIAS; JAKOB, 2020). Os deslocamentos pendulares - expressões contemporâneas da reestruturação do capital e do trabalho e indutores do surgimento de novas centralidades e dinâmicas territoriais - constituem uma ferramenta relevante para avaliar os processos de integração das cidades em contextos regionais que extrapolam a delimitação estritamente político-administrativa (JARDIM, 2011).

A pendularidade de pessoas entre diferentes municípios é um dos principais indicadores de integração regional e revela a importância da mobilidade para o acesso ao mercado de trabalho e às instituições de ensino (MOURA; DELGADO; COSTA, 2013). À medida que as cidades interagem cada vez mais de acordo com suas posições relativas dentro da hierarquia regional, os vínculos interurbanos transcendem com mais frequência os limites municipais, substituindo os laços de longa distância por aqueles com cidades mais próximas (SOJA, 2006).

No Brasil, uma das principais mudanças observadas na dinâmica da população brasileira é o aumento do volume e da representatividade dos fluxos pendulares não somente em locais isolados ou regiões metropolitanas, mas em toda classe de municípios (OJIMA; MARANDOLA JR., 2012). Mesmo que os deslocamentos pendulares ainda sejam predominantemente metropolitanos, há fortes evidências de que "a rede urbana brasileira não apenas se interioriza em termos de desenvolvimento econômico, mas também pela dinâmica demográfica conectada entre municípios de regiões não metropolitanas” (OJIMA; MARANDOLAJR., 2012, p. 108).

No caso específico do estado do Rio de Janeiro, a porção leste fluminense viu a sua estrutura urbana ser modificada em função das atividades ligadas à extração de petróleo e gás natural na Bacia de Campos, que contribuíram para uma alteração na dinâmica demográfica e no mercado de trabalho dos municípios do Norte Fluminense e das Baixadas Litorâneas (SOUZA; FRUTUOZO, 2018; SOUZA; TERRA, 2017, 2020). Três arranjos populacionais pertencentes às duas mesorregiões destacadas (Macaé-Rio das Ostras, Cabo Frio e Campos dos Goytacazes) foram sugeridos pelo IBGE (2015, p. 67) como formas urbanas a serem acompanhadas: "caso o dinamismo econômico nesta região venha a aumentar o movimento de pessoas entre estes três arranjos, levará à criação de uma nova unidade urbana que somará mais de 1,2 milhão de habitantes". A dinâmica territorial desses arranjos populacionais é destacada pelo próprio órgão estatístico como um aspecto relevante da urbanização brasileira.

Dentre as cidades circunscritas nesses três arranjos populacionais, Macaé, conhecida como a capital nacional do petróleo, se reafirma como centro de apoio à exploração do petróleo e aparece como um grande nó da produção petrolífera e principal área de circulação de trabalhadores na região (SILVA, 2017; SOUZA; PASSARELLI-ARAUJO; VASCONCELOS JÚNIOR, 2019). Contudo, pouco ainda se sabe sobre: o peso da pendularidade entre esses 
municípios em comparação à pendularidade total do estado do Rio de Janeiro; o nível de ligações que cada município efetivamente estabelece com os demais; e o nível de interação dos outros municípios com Macaé, que possui o maior saldo pendular e é o principal destino dos pendulares na região.

Esse artigo busca responder às seguintes questões: que diferenças quantitativas se estabelecem nas formas de integração entre Macaé e outros municípios do entorno? Qual é o papel de Macaé no processo recente de urbanização no território fluminense? E, por fim, quais são as implicações trazidas pelo aumento da integração regional no processo de formulação e implementação de políticas públicas comuns entre esses municípios?

A partir da delimitação do problema de pesquisa, o presente estudo busca analisar a integração regional dos municípios do Norte Fluminense e das Baixadas Litorâneas a partir do movimento pendular da população que reside na região. A discussão sobre integração será norteada e construída com base nos dados censitários de 2000 e 2010.

A hipótese aqui colocada vincula-se à noção de que os municípios situados na porção leste fluminense experimentaram um aumento da interação municipal por trabalho e estudo entre 2000 e 2010, induzido diretamente pelo dinamismo econômico de Macaé. Argumentamos que Macaé, espaço que abriga a base da indústria petrolífera, tem se colocado como: principal destino dos movimentos pendulares realizados por trabalho e estudo; maior estabelecedor de conexões efetivas com outros municípios; e principal indutor do aumento dos movimentos pendulares das cidades vizinhas, que, por sua vez, "emprestam" o seu território à cidade de Macaé para atender às demandas por moradia e àquelas do setor industrial e de serviços.

Nas seções seguintes deste artigo, resgatamos a importância da pendularidade como medida de integração regional, seguida pela discussão dos processos de produção e ocupação que historicamente ocorreram na região analisada. A partir da descrição metodológica do trabalho, discutimos a origem, o destino, o volume dos fluxos pendulares e 0 grau de integração entre os municípios do leste fluminense em 2000 e 2010 . Por fim, são apresentadas as considerações finais e as fontes de pesquisa utilizadas para a realização do trabalho.

\section{A pendularidade como indicador de integração regional}

A mobilidade pendular pode ser compreendida, em sentido amplo, como o deslocamento realizado por um indivíduo entre unidades espaciais distintas, cujo local de residência difere do local de trabalho ou de estudo (PEREIRA; HERRERO, 2009). Por se tratar de um fenômeno complexo e dinâmico, a pendularidade também incorpora outros motivos que levam as pessoas a se moverem - consumo, lazer e cultura, por exemplo. No entanto, essas

\footnotetext{
1 “Empréstimo de território" é um conceito introduzido por Araujo (2016). Trata-se da prática de empréstimo de territórios entre cidades, estabelecendo lógicas de relações, interfuncionalidades e contiguidades, para atender à demanda seja por moradia, seja industrial e de serviços especializados.
} 
motivações ainda não são consideradas nas principais fontes de dados disponíveis para análise desses deslocamentos.

Um dos traços mais marcantes da nova ordem mundial é o deslocamento pendular da população (IBGE, 2015). Os movimentos pendulares têm impulsionado o surgimento de novas formas de expansão urbana e figuram como um elemento central na compreensão de dinâmicas de integração regional (PEREIRA; HERRERO, 2009). A análise dos deslocamentos pendulares funciona como uma proxy dos movimentos da economia e da sociedade contemporâneas, responsáveis pela criação de novos espaços e novas dinâmicas sociais e territoriais (JARDIM, 2011).

As ideias de coesão e integração são utilizadas por órgãos estatísticos de diferentes países. Nos Estados Unidos, o Census Bureau adota o movimento pendular por trabalho como critério de delimitação das áreas metropolitanas e o considera uma medida que reflete a integração social e econômica de áreas geográficas (UNITED STATES GOVERNNMENT, 2000). A França também utiliza dados sobre deslocamento pendular como medida de integração e urbanização do território (JULIEN, 2000).

No Brasil, além do tradicional critério demográfico (pendularidade), o IBGE também já considerou, no passado, enquanto critérios de integração para a delimitação de áreas urbanas, o número de ligações telefônicas, a intensidade de fluxos aéreos (de pessoas e/ou de mercadorias), as linhas de transportes coletivos e os fluxos de bens e serviços.

No entanto, a partir de 2015, a análise de integração regional passou a contar com dois critérios principais: contiguidade da mancha urbana e pendularidade - esta última de especial interesse para o presente artigo. Esses dois critérios estão no cerne da definição de um arranjo populacional, entendido como "um agrupamento de dois ou mais municípios onde há uma forte integração populacional devido aos movimentos pendulares para trabalho ou estudo, ou devido à contiguidade entre as manchas urbanizadas principais" (IBGE, 2015, p. 22).

Os censos demográficos são a principal fonte de dados sobre pendularidade. 0 Censo de 1970 foi o primeiro a coletar dados sobre os movimentos pendulares. Essa informação foi utilizada como um dos critérios para a delimitação das primeiras regiões metropolitanas do país (GALVÃO; FAISSAL, 1969). 0 quesito foi mantido no Censo de 1980, suprimido no de 1991 e reincorporado no de 2000. O Censo Demográfico de 2010 não só manteve o quesito, como também abriu novas possibilidades de análise ao investigar os movimentos por trabalho e estudo em questões distintas.

A permanência desse quesito nos dois últimos censos reforça a importância da pendularidade para o entendimento da dinâmica urbana. É justamente nas duas primeiras décadas do século XXI que o país testemunhou um "arrefecimento do processo de metropolização brasileiro, por meio de um movimento de interiorização da atividade econômica e a criação de novas centralidades urbanas”, protagonizadas por cidades médias emergentes industriais, baseadas na dispersão da indústria de transformação (SIMÕES; AMARAL, 2011, p. 554). 
Dentre os inúmeros fatores que se associam à pendularidade, Moura et al. (2005) destacam alguns que podem ser decisivos: a dinâmica do mercado de terras no município-polo dos aglomerados; a alteração do perfil econômico e a desconcentração da indústria para municípios que não o polo ou distritos industriais consagrados; o acesso diferenciado ao mercado de trabalho e/ou oportunidades de estudo; e os custos, a qualidade do transporte disponível e o tempo de deslocamento.

Essa grande transformação urbana reflete o acelerado processo de industrialização da economia brasileira, ensejado pela expansão dos sistemas de transportes e dos meios de comunicação de massas (BRITO; SOUZA, 2005). Os autores argumentam que essa transformação é uma construção irreversível da hegemonia do urbano, não só como o lócus privilegiado das atividades econômicas, mas também como difusora dos novos padrões de relações sociais, de produção e do modo de vida.

A mobilidade como modo de vida substituiu a "dupla ausência", descrita por Abdelmalek Sayad, pela “copresença” (BADIE et al., 2008). 0 termo copresença refere-se aos indivíduos que vivem e usufruem cotidianamente dos serviços oferecidos por dois territórios distintos (um provê o lugar de habitação e o outro provê o trabalho e/ou estudo). É a ideia que exprime essência da integração regional sob a ótica do movimento da população.

A intensificação dos movimentos pendulares também se associa ao conceito de “cidade-região" (SCOTT et al., 2001). A contribuição desse conceito não está restrita ao reconhecimento dos processos socioeconômicos e demográficos que integram as cidades aos seus contextos regionais, mas tem como mérito a necessidade de fomentar a discussão política em espaços integrados e marcados por desafios institucionais comuns (ARRAIS, 2008). No entanto, a questão colocada por Agnew (2000) é que essas regiões raramente coincidem com as regiões político-institucionais; com efeito, há um déficit político na capacidade das cidades-regiões em formularem e implementarem políticas e planos de ação para esses espaços.

Conforme elucidado pelo autor, a integração das cidades no contexto regional torna esses desafios ainda mais evidentes e tão complexos quanto aqueles observados no contexto metropolitano. A formulação e implementação de políticas públicas de desenvolvimento regional devem levar em conta esses desafios, que, por sua vez, se diferenciam entre os municípios de origem e os de destino e dependem significativamente da intensidade dos fluxos.

Para os municípios de origem, a intensa saída da população pode significar um esvaziamento progressivo de mão de obra residente, com impactos diretos na oferta e demanda por serviços públicos municipais. Para os receptores, a intensificação dos fluxos de entrada pode contribuir para o preenchimento dos postos de trabalho, mas também pode comprometer 0 desempenho dos sistemas de transportes públicos (HORNER, 2004), provocar impactos ambientais e acirrar as desigualdades sociais nesses espaços (BRITO; SOUZA, 2005).

Esses fatores corroboram a necessidade de compreender os deslocamentos pendulares como elementos que permitem a formulação de políticas de enfrentamento às deficiências 
de infraestrutura nas cidades interioranas e implementar soluções de planejamento, gestão e governança integrada nestes espaços (MOURA; DELGADO; COSTA, 2013). São esses deslocamentos que tornam evidentes os espaços mais integrados à dinâmica regional e também aqueles que disponibilizam seu território para moradia e para trabalho e/ou estudo. Na tradição dos estudos urbanos, o movimento pendular consolida sua importância para a reprodução capitalista e a compreensão das relações regionais em áreas de forte industrialização que necessitam de grandes contingentes de mão de obra, cuja reprodução a cidade central por si só nem sempre consegue garantir (OJIMA; MARANDOLA JR., 2012).

\section{Dinâmicas de produção e ocupação do leste fluminense}

A análise dos movimentos pendulares entre os municípios dos arranjos populacionais de Campos dos Goytacazes, Macaé-Rio das Ostras e Cabo Frio deve vir acompanhada de uma breve descrição dos processos de produção e ocupação que historicamente ocorreram na região analisada. Apesar de considerarmos todos os municípios do leste fluminense, desde São João da Barra até Arraial do Cabo (Figura 1), é preciso entender que esses municípios apresentavam vocações econômicas distintas no passado.

FIGURA 1

Composição dos arranjos populacionais do leste fluminense Municípios selecionados - 2010

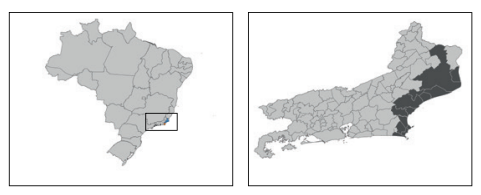

Norte Fluminense

1. Campos dos Goytacazes

2. São João da Barra

3. Macaé

4. Carapebus

5. Conceição de Macabu

6. Quissamã

Baixadas Litorâneas

7. Casimiro de Abreu

8. Rio das Ostras

9. Cabo Frio

10. Armação dos Búzios

11. São Pedro da Aldeia

12. Arraial do Cabo

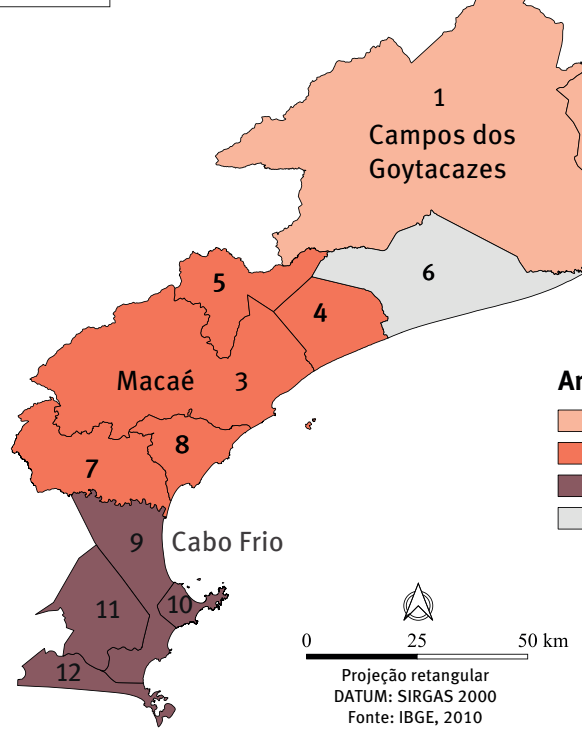

Arranjos populacionais

Campos dos Goytacazes

Macaé - Rio das Ostras

Cabo Frio

Município isolado

Fonte: IBGE, malha digital 2010 
Nas Baixadas Litorâneas, as atividades da indústria salineira moviam a economia local antes da descoberta e início das atividades de exploração de petróleo. A industrialização da região salineira, a partir da década de 1950, intensificou as ondas migratórias internas, sobretudo aquelas com origem no Norte e Noroeste Fluminense, sendo que os fluxos migratórios persistiram nos anos posteriores, como resposta ao processo de desindustrialização na região em questão (PEREIRA, 2010). Além das atividades da indústria salineira, o turismo sempre se destacou como um importante setor da economia dos municípios dessa região (SOUZA; PASSARELLI-ARAUJO; VASCONCELOS JÚNIOR, 2019).

O Norte Fluminense, desde a década de 1970 até a de 1990, tinha uma economia baseada na atividade agroindustrial açucareira. Durante muitos anos, o município de Campos dos Goytacazes figurava como principal polo econômico, principal mercado consumidor e concentrador de grande parte da população da região que, na época, era considerada uma “região-problema” (PIQUET; GIVISIEZ; OLIVEIRA, 2008, p. 40). Tratava-se de uma região economicamente estagnada, com alto grau de desemprego sazonal que acompanhava 0 êxodo rural rumo à periferia das cidades da região (PIQUET, 2003).

A notícia da descoberta de petróleo na plataforma continental marítima na Bacia de Campos, em 1973, inaugurou um novo ciclo econômico na região (PIQUET; GIVISIEZ; OLIVEIRA, 2008). Macaé foi a cidade escolhida para sediar a Unidade Gestora da Petrobrás da Bacia Petrolífera de Campos. A instalação da sede da Petrobrás em Macaé foi um pacto territorial verdadeiramente transformador na dinâmica produtiva da cidade e da região (SILVA, 2017). 0 início das atividades de exploração trouxe um rápido crescimento da população urbana de Macaé, assim como alterou a dinâmica demográfica e a do mercado de trabalho (SOUZA; TERRA, 2017). Em meados dos anos 1970 iniciou-se uma intensa restruturação produtiva, impactando significativamente o mercado de trabalho, que a partir de então passou a estar cada vez mais conectado à economia global (SILVA, 2015).

Em relação à dinâmica urbana, segundo Cruz e Terra (2020), o rápido e intenso fluxo de pessoas provocou uma total reconfiguração funcional da rede regional de cidades. Os autores argumentam que as características concentradoras, de enclave e de elevada polarização das estruturas econômicas montadas em Macaé transformaram o município em polo de trabalho e de atividades empresariais.

As novas possibilidades de trabalho assalariado e com maior remuneração estimularam o movimento de pessoas rumo aos municípios produtores de petróleo, revertendo a tendência de esvaziamento demográfico que refletia diretamente a decadência das atividades econômicas tradicionais no período anterior (SOUZA; TERRA, 2020). Esse processo de industrialização/urbanização reconfigurou o espaço regional e teve como contrapartida imediata o aumento da demanda por mão de obra, que foi suprida, sobretudo, pelas migrações internas e pelos movimentos pendulares (SOUZA; TERRA, 2020).

A maior riqueza gerada por intermédio da economia do petróleo aprofundou a pobreza daqueles que não foram inseridos no mercado de trabalho na região (SILVA, 2017). A nova economia urbana especializada nas atividades petrolíferas criou uma camada da população 
especializada, técnica e com altos rendimentos na região, gerando um padrão de consumo específico na cidade (SILVA, 2015). A autora argumenta que parte dessa população com baixa qualificação, que não se inseriu no espaço urbano de forma a garantir as necessidades básicas, adensou as periferias e as favelas da cidade, sendo incluída na economia urbana por meio do circuito inferior do petróleo.

Cruz e Terra (2020) também ressaltam que o padrão de integração observado nessa região contém vetores de desestruturação socioespacial e econômica do território - agressões severas ao meio ambiente e desestruturação de economias regionais - por uma série de características inerentes a dois grandes projetos de infraestrutura e produção instalada na região, assim como o seu processo de implantação e operação. São eles: o Complexo de Exploração e Produção off shore de Petróleo e Gás da Bacia de Campos e o Complexo Industrial e Portuário do Açu.

Esses grandes projetos urbanos viabilizaram articulações entre a metrópole do Rio de Janeiro e essas porções litorâneas do estado (ARAUJO, 2016). As transformações territoriais, ensejadas pelas alterações das dinâmicas demográfica, econômica e urbana, "modificaram a hierarquia regional existente e Macaé passou a ter um posicionamento estratégico para o desenvolvimento do estado do Rio de Janeiro" (TERRA; AZEVEDO, 2019, p. 464).

A partir desse entendimento, observamos que a relação do território na área de estudo sugere uma forma nova do processo de urbanização, o qual se relaciona também com a metropolização do espaço, ainda que incipiente, na escala regional (SOUZA; TERRA, 2017). A pendularidade (ao lado das migrações) tem sido fundamental para a "continuidade do processo de reprodução do capital, ainda que não resulte em ascensão social dos pendulares, mas simplesmente os mantenha na estrutura social relativa" (SOUZA; TERRA, 2020, p. 176).

\section{Metodologia}

Para compreender as diferenças quantitativas que se estabelecem nas formas de integração entre os municípios do leste fluminense, foram utilizadas informações diretas referentes aos movimentos pendulares contidas nos Censos Demográficos de 2000 e 2010 . Aqui estamos admitindo o conceito mais amplo de pendularidade, tendo em vista as especificidades dos contratos de trabalho - regime de 14 dias trabalhados por 14 dias de folga, de $21 \times 21$, 28x28 e $14 \times 21$ - de muitos dos trabalhadores das indústrias que operam na região. Essa especificidade é um fator adicional que possibilita a dissociação entre o local de trabalho e o local de moradia para um grande número de trabalhadores, na medida em que permite que muitos deles residam em locais mais distantes - em outros estados da federação e inclusive em outros países -, algo que seria impossível se o deslocamento para o trabalho fosse diário.

A partir das informações referentes ao município de residência atual e os municípios em que o indivíduo trabalhava e/ou frequentava a escola, confeccionamos as matrizes origem-destino para os dois decênios, tendo-se o cuidado de selecionar apenas os movimentos restritos ao conjunto de municípios da região estudada. 0 Censo de 2000 indagou o nome 
do município, da UF ou do país estrangeiro onde o indivíduo trabalhava ou estudava. Para aqueles que trabalhavam e estudavam em outro município, priorizava-se a informação relativa ao local de trabalho. Já o Censo de 2010 traz duas questões para a identificação dos pendulares: o município, unidade da federação ou país estrangeiro que frequentava escola ou creche; e o local de trabalho.

As informações censitárias referentes à pendularidade por estudo e trabalho não podem ser diretamente somadas, devido ao erro de dupla contagem. Como forma de contornarmos esse problema, no quesito referente à pendularidade por estudo, consideramos: todos os indivíduos residentes no município "A" que apenas estudam no município "B"; e todos os indivíduos que, além de estudarem em "B”, trabalham no município "C”. Esse procedimento elimina a contagem de uma mesma pessoa duas vezes (pendulares que trabalham e estudam no mesmo município). Após esse filtro, as informações de pendularidade por estudo foram somadas às de pendularidade por trabalho e assim chegamos à pendularidade total, comparável aos valores de 2000.

Para a análise dos movimentos pendulares, calculou-se, para cada município, o Índice de Eficácia Migratória (IEM), desenvolvido por Baeninger (2000) e adaptado por Moura et al. (2013). Embora a pendularidade difira da migração por não implicar transferência ou fixação definitiva de residência (CARVALHO; RIGOTTI, 1998), o IEM é uma ferramenta que pode ser aplicável a diferentes tipos de fluxos para identificar a potencialidade dos deslocamentos populacionais de cada município em termos de entrada e saída da população. Foi preservado o nome do indicador e adaptada a fórmula para a realidade dos deslocamentos pendulares. Desse modo, o IEM corresponde a (entradas - saídas)/(entradas + saídas), variando entre -1 e 1. Valores negativos expressam o predomínio dos fluxos de saída (evasão), enquanto os positivos refletem a capacidade de absorção (recepção) do município.

Para classificar os municípios quanto à direção predominante dos fluxos, Moura et al. (2013) subdividiram a escala do IEM em três porções: valores inferiores ou iguais a -0,2 implicam o predomínio dos fluxos de saídas, classificando o município como evasor; valores superiores ou iguais a 0,2 significam o predomínio dos fluxos de entradas, classificando o município como receptor; e o município cujo índice situa-se entre -0,2 e 0,2 foi classificado como bidirecional, uma vez que se observa, nestes casos, certa equivalência entre saída e entrada de pessoas.

Os fluxos direcionais da pendularidade entre os municípios selecionados foram representados por meio de gráficos de visualização circular, construídos com o pacote Circlize (GU et al., 2014) no software $R$. Tal representação gráfica, amplamente utilizada no campo da genética, foi adaptada para o campo dos estudos populacionais por Sander et al. (2014). Esses gráficos captam as três dimensões de uma matriz origem-destino: entradas, saídas e volume dos fluxos pendulares.

A análise da integração regional foi realizada a partir de um indicador chamado grau de integração regional (GIR), desenvolvido originalmente por Lobo et al. (2017; 2018) e adaptado por Souza et al. (2019). Seguimos os mesmos procedimentos metodológicos utilizados 
pelos últimos autores, como forma de contrapor os dados de 2000 e 2010, em uma perspectiva comparada. Esse indicador incorpora três dimensões analíticas da pendularidade: pendularidade interna; conectividade interna; e pendularidade em direção ao núcleo.

0 grau de pendularidade interna (GPI), primeira dimensão do indicador, resulta do quociente entre os deslocamentos internos com destino a algum dos municípios selecionados $\left(P_{j, M S}\right)$ e a pendularidade total intraestadual, originária em cada um dos municípios selecionados $\left(P_{j, T}\right)$.

$G P I=\frac{P_{j, M S}}{P_{j, T}}$

A segunda dimensão é representada pelo grau de conectividade interna (GCl), que resulta do quociente entre o número de conexões reais $(\mathrm{Cr})$, por trabalho e estudo, estabelecidas por um município com os demais municípios selecionados e o número de conexões possíveis (Cp). Na nossa análise, o número de conexões possíveis será 11, uma vez que estamos trabalhando com um conjunto formado por 12 municípios ( $n-1)$.

$G C I=\frac{C_{r}}{C_{P}}$

Na terceira dimensão do indicador, foi estimado o grau de pendularidade nuclear (GPN), que se refere ao número de pendulares internos (ou seja, entre os municípios selecionados), que tiveram como destino o núcleo - o município de Macaé, no presente estudo. 0 numerador é dado pela pendularidade originária em cada um dos municípios selecionados, com destino a Macaé $\left(P_{\text {Nuclear }}\right)$; no denominador, considerou-se a pendularidade total de cada município, em direção a algum município selecionado, incluindo o núcleo. Todos os indicadores mencionados variam entre 0 e 1 .

$G P N=\frac{P_{\text {Nuclear }}}{P_{j, M S}}$

Finalmente, foram utilizados os graus de pendularidade interna, conectividade interna e pendularidade nuclear para estimar, por média aritmética, o grau de integração regional (GIR):

$G I R=\frac{G P I+G C I+G P N}{3}$

Esse índice varia entre 0 e 1. Na situação de ausência completa de mobilidade interna, o índice será 0; na outra situação extrema, em que toda mobilidade pendular se restrinja aos municípios selecionados, o índice será 1. Embora tais situações sejam improváveis de ser observadas no mundo real, elas servem de referência para a análise dos resultados estimados.

\section{Origem, destino e volume dos fluxos pendulares}

Os indicadores demográficos são um importante meio de revelar a dinâmica populacional apresentada por esses municípios em 2000 e 2010. Os dados sobre a velocidade 
do crescimento da população estão sintetizados na Tabela 1. Observa-se que todos os municípios selecionados cresceram acima da média estadual, tanto entre 2000 e 2010 quanto de 2010 a 2019. Em ambos os períodos, os municípios que mais cresceram foram aqueles do arranjo populacional Macaé-Rio das Ostras, sobretudo Rio das Ostras, que apresentou um excepcional ritmo de crescimento de 10,7\% ao ano entre 2000 e 2010, fruto da dinâmica do mercado imobiliário de Macaé (SOUZA; TERRA, 2015), da expansão do mercado de trabalho da indústria petrolífera e parapetrolífera e da melhoria da estrutura viária. Campos dos Goytacazes é o município com maior concentração de população (507 mil habitantes), mas também figura entre aqueles com menores ritmos de crescimento populacional na região.

Além de Campos dos Goytacazes, todos os outros municípios também experimentaram, no período 2010-2019, redução em seus ritmos de crescimento populacional. Tal diminuição reflete o declínio da fecundidade que vem ocorrendo no estado do Rio de Janeiro, assim como em todo o país (WONG; BONIFÁCIO, 2008), mas nesse caso, além de indicar uma redução dos poderes de atração e retenção, também revela um aumento do poder de expulsão populacional desses municípios, em decorrência da crise econômica dos últimos anos (SOUZA; PASSARELLI-ARAUJO; VASCONCELOS JÚNIOR, 2019). No entanto, mesmo neste cenário, todos os municípios estudados mantiveram um crescimento populacional acima da média estadual (alguns, inclusive, acima da média nacional).

TABELA 1

População residente e taxas de crescimento médio anual Municípios selecionados - 2000-2019

\begin{tabular}{|c|c|c|c|c|c|}
\hline \multirow[t]{2}{*}{ Municípios } & \multicolumn{3}{|c|}{ População } & \multicolumn{2}{|c|}{$\begin{array}{l}\text { Taxa de crescimento } \\
\text { médio anual (\%) (1) }\end{array}$} \\
\hline & 2000 & 2010 & 2019 & $2000-2010$ & 2010-2019 \\
\hline Armação dos Búzios & 18.204 & 27.560 & 33.870 & 4,1 & 2,3 \\
\hline Arraial do Cabo & 23.877 & 27.715 & 30.349 & 1,5 & 1,0 \\
\hline Cabo Frio & 126.828 & 186.227 & 226.525 & 3,8 & 2,2 \\
\hline Campos dos Goytacazes & 407.168 & 463.731 & 507.548 & 1,3 & 1,0 \\
\hline Carapebus & 8.666 & 13.359 & 16.301 & 4,3 & 2,2 \\
\hline Casimiro de Abreu & 22.152 & 35.347 & 44.184 & 4,7 & 2,5 \\
\hline Conceição de Macabu & 18.782 & 21.211 & 23.228 & 1,2 & 1,0 \\
\hline Macaé & 132.461 & 206.728 & 256.672 & 4,5 & 2,4 \\
\hline Quissamã & 13.674 & 20.242 & 24.700 & 3,9 & 2,2 \\
\hline Rio das Ostras & 36.419 & 105.676 & 150.674 & 10,7 & 3,9 \\
\hline São João da Barra & 27.682 & 32.747 & 36.102 & 1,7 & 1,1 \\
\hline São Pedro da Aldeia & 63.227 & 87.875 & 104.476 & 3,3 & 1,9 \\
\hline Total municípios selecionados & 885.466 & 1.208 .176 & 1.454 .629 & 3,1 & 2,1 \\
\hline Estado do Rio de Janeiro & 14.391 .282 & 15.989 .929 & 17.264 .943 & 1,1 & 0,9 \\
\hline Brasil & 169.799 .170 & 190.755.799 & 210.147 .125 & 1,2 & 1,1 \\
\hline
\end{tabular}

Fonte: IBGE. Censos Demográficos de 2000 e 2010 e IBGE Cidades.

(1) Os valores foram obtidos por meio da taxa de crescimento exponencial. Para a descrição da fórmula, consultar Preston et al. (2001, p. 13). 
Analisando especificamente as trocas pendulares entre os municípios selecionados, alguns casos merecem atenção. Armação dos Búzios, Macaé, Cabo Frio e Casimiro de Abreu foram os únicos com saldo pendular positivo em 2000 (Tabela 2). Os dois primeiros figuram como áreas de forte recepção de pendulares, contrastando com Conceição de Macabu - município com forte evasão da população por motivo de trabalho ou estudo. 0 ano de 2010 representou um crescimento de 300\% no número total de pendulares e somente dois municípios registraram saldo pendular positivo: Macaé e Armação dos Búzios. A proeminência de Macaé em relação aos demais municípios o coloca na posição de maior receptor $(41,34 \%)$ dos pendulares e maior retentor de sua população.

Em relação à direção predominante dos fluxos (IEM), seis municípios foram classificados como evasores em 2000: Carapebus, Campos dos Goytacazes, Conceição de Macabu, Quissamã, São João da Barra e São Pedro da Aldeia. Em 2010, Arraial do Cabo e Casimiro de Abreu foram incorporados à lista. Também nesse mesmo período, somente Cabo Frio e São João da Barra podem ser classificados como bidirecionais (casos em que há certa equivalência entre entrada e saída de pessoas). Na categoria dos municípios receptores, somente Armação dos Búzios e Macaé estão presentes e com um elevado IEM em ambos os períodos. No entanto, ao contrário de Macaé, que seguiu uma trajetória ascendente de recepção de pendulares e retenção dos seus trabalhadores, Búzios demonstrou um declínio de 9\% em relação à sua capacidade de recepção de 2000 para 2010 (Tabela 2).

Também chamamos a atenção para o número elevado de pendulares que partiram de São Pedro da Aldeia e a permanência do padrão de Campos dos Goytacazes, que, embora seja o mais populoso e tenha sido por muito tempo centralidade regional, demonstrou saldo pendular e IEM negativos nos dois períodos analisados.

TABELA 2

Indicadores de pendularidade

Municípios selecionados - 2000-2010

\begin{tabular}{|c|c|c|c|c|c|c|c|c|}
\hline \multirow[b]{2}{*}{ Municípios } & \multicolumn{4}{|c|}{2000} & \multicolumn{4}{|c|}{2010} \\
\hline & $\begin{array}{c}\text { Entradas } \\
\text { (E) }\end{array}$ & $\begin{array}{l}\text { Saídas } \\
\text { (S) }\end{array}$ & $\mathrm{E}-\mathrm{S}$ & $\begin{array}{c}\text { IEM (E-S)/ } \\
(E+S)\end{array}$ & $\begin{array}{l}\text { Entradas } \\
\text { (E) }\end{array}$ & $\begin{array}{l}\text { Saídas } \\
\text { (S) }\end{array}$ & E-S & $\begin{array}{c}\text { IEM (E-S)/ } \\
(E+S)\end{array}$ \\
\hline Armação dos Búzios & 2.972 & 258 & 2.714 & 0,84 & 7.245 & 1.027 & 6.218 & 0,75 \\
\hline Arraial do Cabo & 804 & 1.125 & -321 & $-0,17$ & 1.334 & 2.324 & -990 & $-0,27$ \\
\hline Cabo Frio & 6.713 & 6.020 & 693 & 0,05 & 15.630 & 16.298 & -668 & $-0,02$ \\
\hline Carapebus & 343 & 560 & -217 & $-0,24$ & 338 & 2.799 & -2.461 & $-0,78$ \\
\hline Campos dos Goytacazes & 1.977 & 3.789 & -1.812 & $-0,31$ & 4.966 & 9.183 & -4.217 & $-0,30$ \\
\hline Casimiro de Abreu & 1.694 & 1.370 & 324 & 0,11 & 3.472 & 5.704 & -2.232 & $-0,24$ \\
\hline Conceição de Macabu & 107 & 1.709 & -1.602 & $-0,88$ & 248 & 3.321 & -3073 & $-0,86$ \\
\hline Macaé & 7.436 & 829 & 6.607 & 0,80 & 31.248 & 2.088 & 29.160 & 0,87 \\
\hline Quissamã & 239 & 649 & -410 & $-0,46$ & 671 & 1.630 & -959 & $-0,42$ \\
\hline Rio das Ostras & 1.288 & 1.464 & -176 & $-0,06$ & 6.548 & 14.811 & -8.263 & $-0,39$ \\
\hline São João da Barra & 434 & 1.222 & -788 & $-0,48$ & 1.803 & 2.417 & -614 & $-0,15$ \\
\hline São Pedro da Aldeia & 916 & 5.928 & -5.012 & $-0,73$ & 2.088 & 13.989 & -11.901 & $-0,74$ \\
\hline Total & 24.923 & 24.923 & 0 & 0 & 75.591 & 75.591 & 0 & 0 \\
\hline
\end{tabular}

Fonte: IBGE. Censos Demográficos de 2000 e 2010. 
A visualização das origens, destino e volume dos fluxos pendulares são uma estratégia fundamental para identificação dos padrões espaciais em uma região. A Figura 2 captura a dinâmica dos fluxos observados e representa visualmente as matrizes origem-destino dos pendulares em 2000 e 2010. A origem e o destino dos pendulares são representados pelos segmentos (setas) do diagrama de visualização circular. A magnitude do fluxo é indicada pela largura das setas. As marcas de escala, representadas em milhares, também podem ser observadas na parte externa dos segmentos do círculo.

Os padrões de pendularidade em 2000 e 2010 são notavelmente diferentes em termos de intensidade dos fluxos. Em 2000, Macaé e Cabo Frio se destacavam como principais destinos dos pendulares. Macaé recebia 7,4 mil trabalhadores e/ou estudantes ( $29 \%$ em relação ao total), dos quais 39,9\% residiam em Campos dos Goytacazes (Figura 2). Os fluxos eram majoritariamente por trabalho. Os municípios de Conceição de Macabu e Rio das Ostras respondiam, respectivamente, por 18,5\% e 15,7\% dos fluxos pendulares em direção a Macaé.

Cabo Frio, município mais populoso das Baixadas Litorâneas, era destino de 6,7 mil pendulares que para lá se deslocavam para trabalhar e/ou estudar. São Pedro da Aldeia era o município de residência de $78 \%$ desses pendulares. A distância $(15 \mathrm{~km})$ e o tempo do deslocamento (aproximadamente 20 minutos pela RJ-140) são variáveis importantes para a explicação da considerável densidade pendular observada no corredor São Pedro da Aldeia-Cabo Frio. No caso específico de Campos dos Goytacazes, com número de entradas na ordem de 1,98 mil pessoas, São João da Barra era responsável por $53 \%$ dos pendulares com destino ao município. A proximidade espacial e a via de acesso (BR-356) também possibilitam a pendularidade entre eles.

0 ano de 2010 é marcado pela intensificação do movimento de pessoas entre os municípios analisados, observada pela notável expansão da largura das setas direcionais (Figura 2). Macaé foi destino de $41,3 \%$ dos 75,5 mil pendulares que circulavam entre os municípios da região, recebendo majoritariamente pessoas que se deslocavam por motivo de trabalho. Rio das Ostras (contíguo a Macaé) era a principal origem dos pendulares: 12,5 mil pessoas (40\%). Cabe ressaltar que esse município é caracterizado por Souza e Terra (2015) como "cidade-dormitório", emprestando o seu território a Macaé, para responder seja à demanda por moradia, seja à demanda industrial e de serviços especializados (ARAUJO, 2016).

Macaé é o município centralizador de entradas na região. Ele é também, ao mesmo tempo, o maior retentor de seus trabalhadores e estudantes - comprovado pelo menor número de saídas entre os municípios selecionados. 0 corredor São Pedro da AldeiaCabo Frio detém o segundo fluxo de maior adensamento na região: 11,8 mil pessoas se movimentando, majoritariamente, por trabalho. A relação entre esses municípios já era observada em 2000. 
FIGURA 2

Origem, destino e densidade dos fluxos pendulares Municípios selecionados - 2000-2010
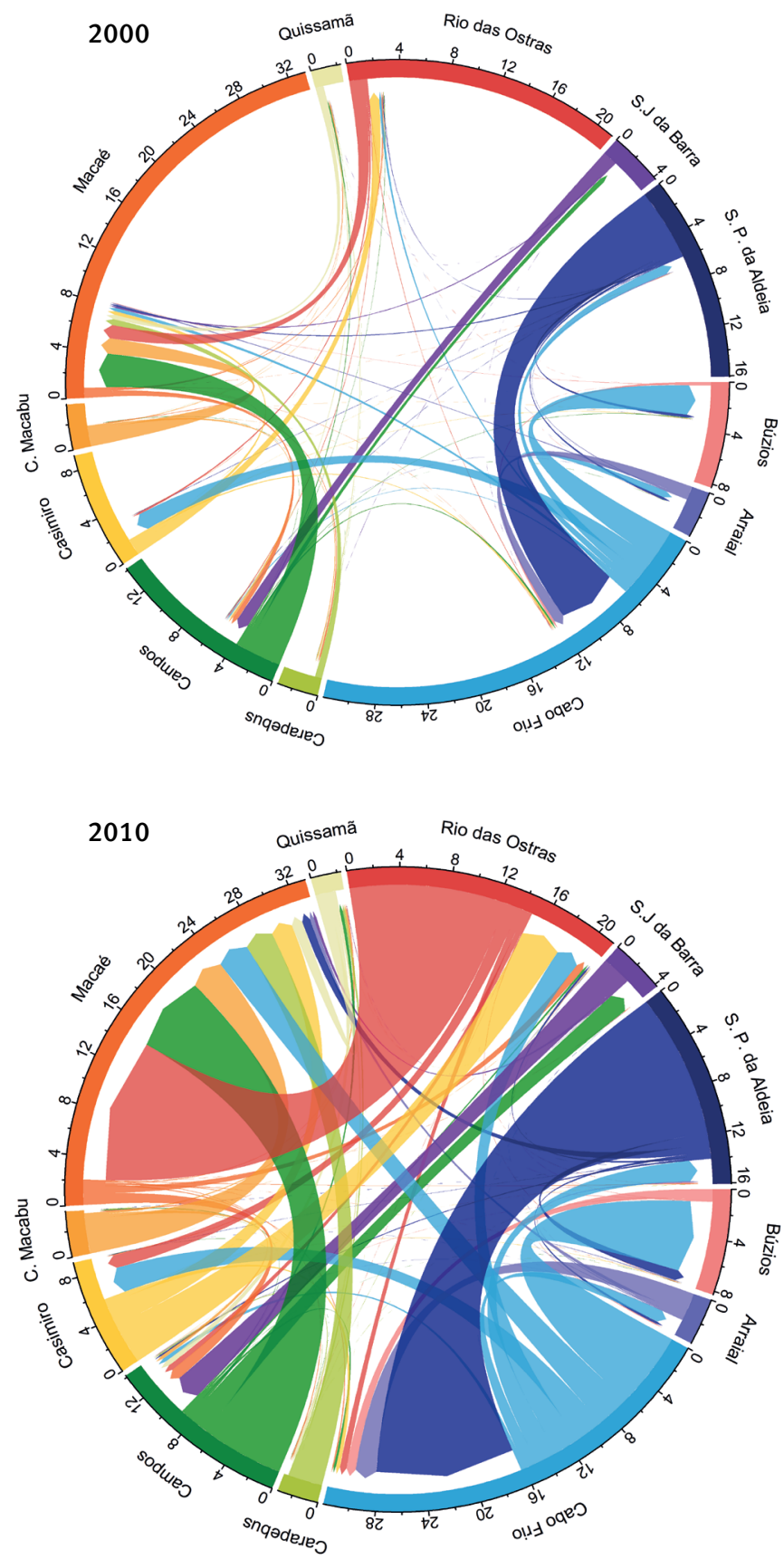

Fonte: IBGE. Censos Demográficos de 2000 e 2010. 
Quanto aos demais municípios (exceto São Pedro da Aldeia, São João da Barra e Armação dos Búzios), Macaé é sempre o destino prioritário. Esse padrão indica uma relação de interdependência entre os municípios. Se, por um lado, os municípios de menor porte precisam do mercado de trabalho de Macaé para absorção de sua mão de obra, por outro, se não fossem os movimentos pendulares, muitos postos de trabalho em Macaé não seriam preenchidos ou o seriam apenas pelas migrações internas. Essa relação de interdependência foi discutida por Souza e Terra (2015) por meio da estimativa do nível de dependência de mão de obra exógena.

A partir dessas constatações, no contexto da pendularidade por trabalho e estudo entre os municípios selecionados, afirmamos que Macaé é o polarizador e principal movimentador do mercado de trabalho regional em 2010. Esse é o principal motivo pelo qual consideramos Macaé o "núcleo" para a estimativa do grau de integração regional, discutido na seção seguinte.

\section{Grau de integração regional no leste fluminense}

Ao analisar os resultados referentes às três dimensões da pendularidade (pendularidade interna, conectividade interna e pendularidade nuclear), observamos sensíveis diferenças nos níveis de integração no conjunto dos municípios estudados (Tabela 3). Em 2000, todos os valores correspondentes à pendularidade interna entre os municípios selecionados apresentaram-se inferiores a 0,5. Essa situação sugere que a maior pendularidade observada na região se dava para algum município fluminense diferente daqueles pertencentes à região analisada.

Entre 2000 e 2010, observam-se mudanças significativas no padrão da pendularidade que envolve estes municípios. Chamam a atenção o crescimento do volume absoluto dos fluxos pendulares internos e a redução da pendularidade originária nesses municípios para os demais municípios fluminenses. Essa mudança se reflete nos índices de pendularidade, que, para 2010, apresentaram-se elevados e significativamente superiores àqueles verificados para 2000, indicando um aumento da integração entre os municípios selecionados.

Carapebus foi o município com maior variação do grau de pendularidade interna (GPI) entre 2000 e 2010. No último período analisado, o município registrou um GPI extremamente elevado de 0,99 (Tabela 3). Esse valor indica que 99 a cada 100 trabalhadores e/ou estudantes pendulares tinham algum dos municípios selecionados como destino. A propósito, Macaé era o principal destino dos pendulares, atraindo $88 \%$ desses indivíduos de Carapebus. Os resultados reafirmam a assertiva de Souza e Terra (2015) sobre a possível transformação de Carapebus, Casimiro de Abreu e Rio das Ostras, todos nas proximidades de Macaé, em cidades-dormitório.

Em relação ao grau de conectividade interna $(\mathrm{GCl})$, apenas Campos dos Goytacazes e Macaé podem ser classificados como municípios com alta conectividade pendular, em razão do elevado número de ligações efetivas expressas por eles (Tabela 3). Em contrapartida, Carapebus e Armação dos Búzios tiveram o menor nível de ligações efetivas. 
Em 2010, apenas dois municípios (Campos dos Goytacazes e Casimiro de Abreu) mantiveram o mesmo número de ligações estabelecidas em 2000. Conceição de Macabu e São João da Barra foram os únicos que perderam conexões internas nesse período. Para todos os outros, o número de conexões internas se expandiu. Note-se que Macaé não estabelece conexão efetiva somente com Arraial do Cabo. A distância (107 km pela Rodovia Amaral Peixoto e 150,2 km via BR-101 e RJ-140) é um fator importante a ser considerado, mas também cabe destacar a proeminência do setor da pesca e do turismo no município e sua particular integração com Cabo Frio, município núcleo do arranjo populacional que Arraial do Cabo faz parte.

No que diz respeito à interação dos demais municípios com Macaé, aqueles situados ao norte da região estudada apresentaram um maior fluxo de pendulares com destino ao núcleo em 2000. O resultado já era esperado e encontra-se ancorado em três fatores: proximidade espacial; concentração das indústrias petrolíferas, contrastando com a ausência de setores industriais desenvolvidos nos municípios mais ao norte; e ausência de um setor turístico desenvolvido nos municípios mais ao sul.

A baixa interação dos municípios mais ao sul - Arraial do Cabo, Armação dos Búzios, Cabo Frio e São Pedro da Aldeia - com Macaé, em 2010, relaciona-se ao desenvolvimento do turismo na região dos lagos, à importância da indústria salineira como absorvedora de mão de obra local e à maior proximidade espacial com a Região Metropolitana do Rio de Janeiro. Os valores expressos pelo GPN mantiveram-se mais elevados para os municípios mais ao norte (excetuando-se São João da Barra) e mais baixos em relação aos municípios mais ao sul. Nesse aspecto, observa-se um mesmo padrão de comportamento nos dois decênios estudados pelas mesmas justificativas.

TABELA 3

Graus de pendularidade interna, conectividade interna e pendularidade nuclear Municípios selecionados - 2000-2010

\begin{tabular}{|c|c|c|c|c|c|c|c|c|c|}
\hline \multirow[t]{2}{*}{ Municípios } & \multicolumn{3}{|c|}{$\begin{array}{l}\text { Pendularidade interna } \\
\text { (GPI) }\end{array}$} & \multicolumn{3}{|c|}{$\begin{array}{c}\text { Conectividade interna } \\
\text { (GCI) }\end{array}$} & \multicolumn{3}{|c|}{$\begin{array}{c}\text { Pendularidade nuclear } \\
\text { (GPN) }\end{array}$} \\
\hline & 2000 & 2010 & $\Delta$ & 2000 & 2010 & $\Delta$ & 2000 & 2010 & $\Delta$ \\
\hline Armação dos Búzios & 0,41 & 0,79 & 0,38 & 0,36 & 0,55 & 0,19 & 0,15 & 0,01 & $-0,14$ \\
\hline Arraial do Cabo & 0,44 & 0,75 & 0,31 & 0,55 & 0,64 & 0,09 & 0,09 & 0,14 & 0,05 \\
\hline Cabo Frio & 0,43 & 0,83 & 0,40 & 0,64 & 0,73 & 0,09 & 0,05 & 0,17 & 0,12 \\
\hline Carapebus & 0,49 & 0,99 & 0,50 & 0,27 & 0,64 & 0,37 & 0,93 & 0,87 & $-0,06$ \\
\hline Campos dos Goytacazes & 0,4 & 0,72 & 0,32 & 0,82 & 0,82 & 0 & 0,78 & 0,72 & $-0,06$ \\
\hline Casimiro de Abreu & 0,45 & 0,85 & 0,40 & 0,64 & 0,64 & 0 & 0,23 & 0,32 & 0,09 \\
\hline Conceição de Macabu & 0,47 & 0,91 & 0,44 & 0,64 & 0,55 & $-0,09$ & 0,8 & 0,86 & 0,06 \\
\hline Macaé & 0,34 & 0,58 & 0,24 & 0,73 & 0,91 & 0,18 & - & - & - \\
\hline Quissamã & 0,46 & 0,94 & 0,48 & 0,55 & 0,64 & 0,09 & 0,61 & 0,57 & $-0,04$ \\
\hline Rio das Ostras & 0,44 & 0,88 & 0,44 & 0,45 & 0,82 & 0,37 & 0,8 & 0,85 & 0,05 \\
\hline São João da Barra & 0,48 & 0,92 & 0,44 & 0,55 & 0,36 & $-0,19$ & 0,1 & 0,09 & $-0,01$ \\
\hline São Pedro da Aldeia & 0,44 & 0,83 & 0,39 & 0,64 & 0,82 & 0,18 & 0,02 & 0,05 & 0,03 \\
\hline
\end{tabular}

Fonte: IBGE. Censos Demográficos de 2000 e 2010. 
A média aritmética destas estimativas revela os elevados graus de integração regional (GIR) nos dois períodos analisados (Figura 3). Em 2000, a maior integração era observada entre os municípios do Norte Fluminense. Campos dos Goytacazes era o município com o maior grau de integração $(0,67)$. São João da Barra protagonizou a menor interação com Macaé, dentre os municípios do Norte Fluminense. No entanto, chamamos a atenção para os municípios do arranjo populacional de Cabo Frio, que, apesar de se integrarem em menor intensidade, já se mostravam influenciados pelo dinamismo econômico de Macaé. Dois fatores ajudam a compreender esse cenário: o dinamismo econômico próprio dos municípios litorâneos diretamente associado ao turismo e à indústria salineira; e a polarização exercida pela Região Metropolitana do Rio de Janeiro nesse arranjo.

Note-se também o aumento do nível de integração de todos os municípios selecionados com o núcleo, entre 2000 e 2010. Rio das Ostras e Carapebus registraram as maiores variações positivas: 0,29 e 0,27, respectivamente. São João da Barra não somente manteve sua posição de município do Norte Fluminense menos integrado a Macaé em 2010, como também assumiu o penúltimo lugar na escala de integração (Armação dos Búzios permaneceu na última colocação). Trata-se do município com a menor variação, ainda que positiva, entre os períodos. Essa situação revela que o maior dinamismo de São João da Barra é com Campos dos Goytacazes, município núcleo do arranjo ao qual ele faz parte.

FIGURA 3

Grau de integração regional

Municípios selecionados - 2000-2010

\section{Norte Fluminense}

1. Campos dos Goytacazes

2. São João da Barra

3. Macaé

4. Carapebus

5. Conceição de Macabu

6. Quissamã

\section{Baixadas Litorâneas}

7. Casimiro de Abreu

8. Rio das Ostras

9. Cabo Frio

10. Armação dos Búzios

11. São Pedro da Aldeia

12. Arraial do Cabo
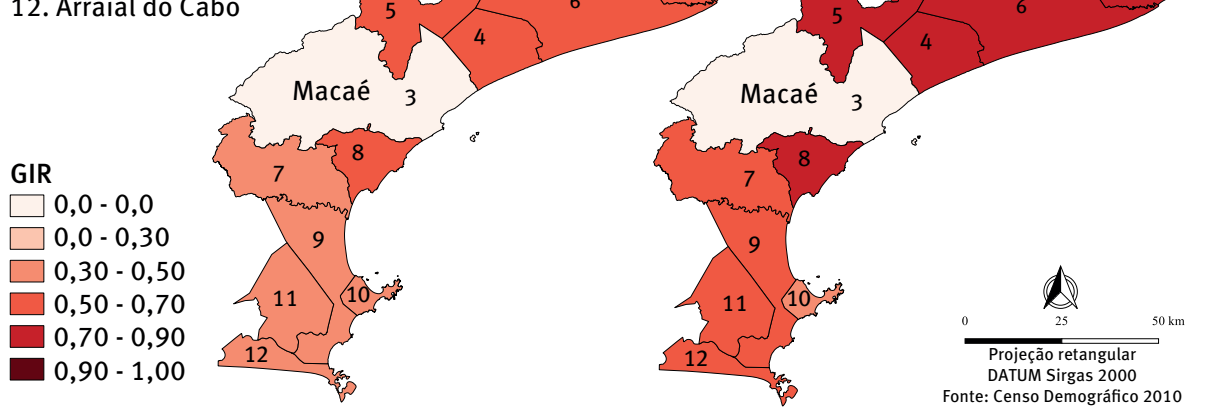

Fonte: IBGE. Censos Demográficos de 2000 e 2010. 
Por fim, é interessante observar o caso específico de Cabo Frio. 0 município teve a terceira maior variação do GIR, somente atrás de Rio das Ostras e Carapebus. Ao contrário desses dois municípios, que estabelecem uma relação de vizinhança com o núcleo e pertencem ao mesmo arranjo populacional de Macaé, a situação de Cabo Frio é reveladora da crescente coesão no vetor leste fluminense. Esse cenário nos leva a constatar que o arranjo populacional de Cabo frio, capitaneado pelo município homônimo, apresenta-se cada vez mais integrado com os municípios do Norte Fluminense, especialmente com Macaé.

\section{Considerações finais}

Este trabalho buscou avaliar o grau de integração regional dos municípios situados no leste fluminense, a partir dos movimentos pendulares retratados pelos Censos Demográficos de 2000 e 2010. A metodologia utilizada permitiu compreender três dimensões analíticas da pendularidade: pendularidade interna; conectividade interna; e fluxos pendulares em direção ao núcleo regional - Macaé. Os resultados observados podem ser sintetizados em três conclusões gerais:

- em primeiro lugar, a pendularidade por trabalho e/ou estudo observada em Macaé coloca o município em posição de destaque entre aqueles selecionados. Portanto, Macaé é uma cidade não apenas em movimento, mas também com potencial de integrar o mercado de trabalho das demais municipalidades da região. É em torno desse município que o tecido urbano regional tem se reorganizado;

- se, em 2000, a pendularidade interna refletia uma situação de predominância dos fluxos para outros municípios fluminenses diferentes daqueles pertencentes à região analisada, o ano 2010 foi marcado pela intensificação dos fluxos pendulares internos e pela redução da pendularidade originária nesses municípios para os demais do estado do Rio de Janeiro;

- todos os municípios selecionados, sem exceção, expandiram seu grau de integração com Macaé em 2010, até mesmo aqueles do arranjo populacional de Cabo Frio, que apresentam um dinamismo econômico próprio devido ao turismo e à indústria salineira.

Esse cenário reforça a necessidade de ordens de ação relativas às estratégias de integração e desenvolvimento regional nesses espaços. A análise das informações e dos resultados apresentados evoca a necessidade de novas investigações que busquem qualificar os movimentos pendulares e compreender a nova lógica de funcionamento das cidades, sobretudo o papel de Macaé e dos demais municípios na reestruturação da ordem urbana e regional que tem ocorrido no vetor leste fluminense.

Reconhecemos que a integração regional, sinalizada pelos movimentos populacionais, deve implicar a construção de uma agenda política de interesses comuns. Lamentavelmente, apesar da crescente integração, esse território ainda é marcado pela pulverização do poder 
político e por um padrão de cooperação intermunicipal amplamente fragilizado (TERRA; AZEVEDO, 2019).

De posse do diagnóstico apresentado, caberá aos atores locais reunirem forças para contornar esses problemas relativos à fragilidade das estruturas regionais a partir da formulação de políticas e planos de ação comuns entre os municípios do leste fluminense. Essas políticas terão que lidar com os efeitos provocados pelo aumento dos movimentos pendulares (impactos nas infraestruturas viárias, nas condições de circulação, na demanda por bens e serviços, entre outros) e deverão buscar respostas para além da escala municipal.

De todo modo, esse estudo pode iluminar novas discussões sobre os padrões de mobilidade no interior do estado do Rio de Janeiro e subsidiar os debates sobre a gestão e governança da região. Algumas questões inerentes a esses municípios ainda permanecem em aberto: existem diferenças significativas entre o perfil socioeconômico da mão de obra que se desloca entre os municípios? De que maneira o setor do petróleo tem remodelado e integrado as populações desses espaços? São questões que merecem maior atenção em pesquisas futuras, sobretudo por se tratar de uma região demograficamente integrada, mas politicamente fragmentada.

\section{Referências}

AGNEW, J. From the political economy of regions to regional political economy. Progress in Human Geography, v. 24, n. 1, p. 101-110, Mar. 2000.

ARAUJO, E. C. de. Processos recentes de urbanização em território fluminense: o fenômeno da dispersão sob a ótica da influência de grandes projetos urbanos. In: OJIMA, R.; MARANDOLA JR., E. (ed.). Dispersão urbana e mobilidade populacional: implicações para o planejamento urbano e regional. 1. ed. São Paulo: Blücher, 2016. p. 91-111.

ARRAIS, T. A. A cidade e a região/a cidade-região: reconhecer processos e construir políticas. Cadernos Metrópole, v. 20, n. 2, p. 81-91, 2008.

BADIE, B. et al. Migration: a new perspective - Building Global Governance. 2. ed. Paris: Éditions La Découverte, 2008.

BAENINGER, R. Região, metrópole e interior: espaços ganhadores e espaços perdedores nas migrações recentes no Brasil, 1980-1996. Campinas: Nepo/Unicamp, 2000. (Textos Nepo, n. 35).

BRITO, F.; SOUZA, J. de. Expansão urbana nas grandes metrópoles: o significado das migrações intrametropolitanas e da mobilidade pendular na reprodução da pobreza. São Paulo em Perspectiva, v. 19, n. 4, p. 48-63, 2005.

CARVALHO, J. A. M.; RIGOTTI, J. I. R. Os dados censitários brasileiros sobre migrações internas: algumas sugestões de análise. Revista Brasileira de Estudos de População, v. 15, n. 2, p. 7-17, 1998.

CRUZ, J. L.; TERRA, D. C. T. Petróleo e porto no norte do estado do Rio de Janeiro, Brasil. Eure, v. 46, n. 139, p. 189-208, 2020.

CUNHA, J. M. P. da; FARIAS, L. A. C. de; JAKOB, A. A. E. Uma periferia, dois centros: o município de Praia Grande no contexto da formação da macrometrópole paulista no começo do século XXI. Revista Brasileira de Estudos de População, v. 37, p. 1-28, 2020. 
GALVÃO, M. V.; FAISSAL, S. Áreas de pesquisa para determinação de áreas metropolitanas. Revista Geográfica, n. 70, p. 57-89, jun. 1969.

GU, Z. et al. Circlize implements and enhances circular visualization in R. Bioinformatics, v. 30, n. 19, p. 2811-2812, June 2014.

HORNER, M. W. Spatial dimensions of urban commuting: a review of major issues and their implications for future geographic research. The Professional Geographer, v. 56, n. 2, p. 160-173, 2004.

INSTITUTO BRASILEIRO DE GEOGRAFIA E ESTATÍSTICA - IBGE. Arranjos populacionais e concentrações urbanas no Brasil. 2. ed. Rio de Janeiro, 2015.

JARDIM, A. de P. Reflexões sobre a mobilidade pendular. In: OLIVEIRA, L. A. P. de; OLIVEIRA, A. T. R. (ed.). Reflexões sobre os deslocamentos populacionais no Brasil. 1. ed. Rio de Janeiro: Instituto Brasileiro de Geografia e Estatística - IBGE, 2011. p. 58-70.

JULIEN, M. P. Mesurer un univers urbain en expansion. Economie et Statistique, v. 336, n. 1, p. 3-33, 2000.

LOBO, C. et al. Mobilidade pendular e a integração metropolitana: uma proposta metodológica para os municípios da Região Metropolitana de Belo Horizonte/MG - 2010. Revista Brasileira de Estudos de População, v. 34, n. 2, p. 321-339, 2017.

LOBO, C.; CARDOSO, L.; ALMEIDA, I. L. de. Mobilidade pendular e integração regional: uma metodologia de análise para as regiões metropolitanas de Belo Horizonte, Rio de Janeiro e São Paulo. Cadernos Metrópole, v. 20, n. 41, p. 171-189, 2018.

MOURA, R.; CASTELLO BRANCO, M. L. G.; FIRKOWSKI, O. L. C. de F. Movimento pendular e perspectivas de pesquisas em aglomerados urbanos. São Paulo em Perspectiva, v. 19, n. 4, p. 121-133, 2005.

MOURA, R.; DELGADO, P.; COSTA, M. A. Movimento pendular e políticas públicas: algumas possibilidades inspiradas numa tipologia dos municípios brasileiros. In: BOUERI, R.; COSTA, M. A. (ed.). Brasil em desenvolvimento 2013: Estado, planejamento e políticas públicas. Brasília: Instituto de Pesquisa Econômica Aplicada, 2013. p. 665-688.

OJIMA, R.; MARANDOLA JR., E. Mobilidade populacional e um novo significado para as cidades: dispersão urbana e reflexiva na dinâmica regional não metropolitana. Revista Brasileira de Estudos Urbanos e Regionais, v. 14, n. 2, p. 103-116, 2012.

PEREIRA, R. H. M.; HERRERO, V. Mobilidade pendular: uma proposta teórico-metodológica. 1. ed. Brasília: Instituto de Pesquisa Econômica Aplicada, 2009.

PEREIRA, W. L. de M. História e região: inovação e industrialização na economia salineira fluminense. Revista de História Regional, v. 15, n. 2, p. 184-210, 2010.

PIQUET, R. Norte Fluminense: mudanças e incertezas na era do petróleo. In: II SEMINÁRIO INTERNACIONAL SOBRE DESENVOLVIMENTO REGIONAL. Anais [...]. Santa Cruz do Sul-RS: Universidade Santa Cruz - Unisc, 2003.

PIQUET, R.; GIVISIEZ, G. H. N.; OLIVEIRA, E. L. de. A nova centralidade de Campos dos Goytacazes: o velho e o novo contexto regional. RDE - Revista de Desenvolvimento Econômico, v. 9, n. 16, p. 39-58, 2008.

PRESTON, S. H.; HEUVELINE, P.; GUILLOT, M. Demography: measuring and modeling population process. 1. ed. Oxford: Blackwell Publishing, 2001.

SANDER, N. et al. Visualising migration flow data with circular plots. Vienna: Vienna Institute of Demography, 2014. (Working Papers, v. 2). 
SCOTT, A. et al. Cidades-regiões globais. Espaço \& Debates, v. 41, n. 1, p. 11-25, 2001.

SILVA, S. C. da. Globalização e o circuito espacial de produção petrolífero: as cidades da informação e as cidades da extração. In: XI ENCONTRO NACIONAL DA ANPEGE. Anais [...]. Presidente Prudente-SP: Associação Nacional de Pós-Graduação e Pesquisa em Geografia, 2015.

SILVA, S. C. da. O circuito espacial de produção do petróleo: rede urbana e escalas de poder. In:XVII ENANPUR. Anais [...]. São Paulo: Associação Nacional de Pós-Graduação e Pesquisa em Planejamento Urbano e Regional, 2017.

SIMÕES, R.; AMARAL, P. V. Interiorização e novas centralidades urbanas: uma visão prospectiva para o Brasil. Economia, v. 12, n. 3, p. 553-579, 2011.

SOJA, E. W. On the concept of global city regions. Art-e-Fact, n. 4, 2006. Disponivel em: http:// artefact.mi2.hr/_a04/lang_en/theory_soja_en.htm. Acesso em: 15 ago. 2020.

SOUZA, J. de; FRUTUOZO, J. V. de P. Rio de Janeiro: considerações sobre os processos de expansão urbana e interiorização do crescimento (1980-2010). urbe. Revista Brasileira de Gestão Urbana, v. 10, n. 1, p. 124-139, 2018.

SOUZA, J. de; PASSARELLI-ARAUJO, H.; POHLMANN, M. de O. Rio de Janeiro e novas urbanidades: reflexões sobre a integração regional do litoral norte fluminense e os desafios à governança supralocal. In: XVIII ENANPUR. Anais [...]. Natal-RN: Associação Nacional de Pós-Graduação e Pesquisa em Planejamento Urbano e Regional, 2019.

SOUZA, J. de; PASSARELLI-ARAUJO, H.; VASCONCELOS JÚNIOR, A. F. da S. Macaé: uma cidade em movimento. In: SILVA, S. R. de A. E.; CARVALHO, M. R. de (ed.). Macaé, do caos ao conhecimento: olhares acadêmicos sobre o cenário de crise econômica. 1. ed. Macaé-RJ: Observatório da Cidade de Macaé, 2019. p. 64-80.

SOUZA, J. de; TERRA, D. C. T. Indústria petrolífera, mercado de trabalho e nível de dependência da mão de obra exógena nos municípios produtores de petróleo da Bacia de Campos, RJ. Revista Brasileira de Estudos Urbanos e Regionais, v. 17, n. 1, p. 123, 2015.

SOUZA, J. de; TERRA, D. C. T. Rio de Janeiro: rumo a uma nova região metropolitana? Cadernos Metrópole, v. 19, n. 40, p. 817-840, 2017.

SOUZA, J. de; TERRA, D. C. T. Migrações, pendularidades e mercado de trabalho no segmento upstream da indústria do petróleo na Bacia de Campos. Eure, v. 46, n. 137, p. 157-180, 2020.

TERRA, D. C. T.; AZEVEDO, N. L. de. Limites e possibilidades da construção de arranjos político-institucionais de cooperação intermunicipal na Bacia de Campos. In: SILVA, S. R. de A. E.; CARVALHO, M. R. de (ed.). Macaé, do caos ao conhecimento: olhares acadêmicos sobre o cenário de crise econômica. 1. ed. Macaé: Prefeitura Municipal de Macaé, 2019. p. 459-502.

UNITED STATES GOVERNNMENT. Federal Register, v. 65, n. 249, 2000.

WONG, L. L. R.; BONIFÁCIO, G. M. Evidências da diminuição do tamanho das coortes brasileiras: fecundidade abaixo do nível de reposição nas principais regiões metropolitanas - 2004 a 2006. In:XVI ENCONTRO NACIONAL DE ESTUDOS POPULACIONAIS. Anais [...]. Caxambu-MG: Abep, 2008.

\section{Sobre os autores}

Hisrael Passarelli-Araujo é mestrando em Demografia pelo Centro de Desenvolvimento e Planejamento Regional (Cedeplar) da Universidade Federal de Minas Gerais (UFMG) e bacharel em Administração Pública pela Universidade Estadual do Norte Fluminense Darcy Ribeiro (Uenf). 
Joseane de Souza é doutora em Demografia pelo Centro de Desenvolvimento e Planejamento Regional (Cedeplar) da Universidade Federal de Minas Gerais (UFMG). Professora associada da Universidade Estadual do Norte Fluminense Darcy Ribeiro (Uenf).

\section{Endereço para correspondência}

Hisrael Passarelli-Araujo

Rua Professor Domício Murta, 370, apto. 202, Bairro Ouro Preto

31330-670 - Belo Horizonte-MG, Brasil

Joseane de Souza

Universidade Estadual do Norte Fluminense Darcy Ribeiro, Centro de Ciências do Homem

Avenida Alberto Lamego, 2000, Parque Califórnia

28013-602 - Campos dos Goytacazes-RJ, Brasil

\section{Abstract}

Commuting and regional integration in eastern Rio de Janeiro

Commuting is an important measure to assess cities' integration processes and regional population dynamics. In 2015, IBGE identified an intensification of the movement of people between the municipalities in eastern Rio de Janeiro, from Arraial do Cabo to São João da Barra, considering them relevant aspects of Brazilian urbanization. However, little is known about the weight of commuting between these municipalities, the levels of connections between them and the interaction between these municipalities and Macaé, the main destination of commuters in the area. This work analyzes the extent of regional integration of the eastern Rio de Janeiro vector from the 2000 and 2010 census data. The commuting due to work and/or study observed in Macaé places the municipality in a prominent position among the selected municipalities. We affirm that Macaé is not just a moving city, but a municipality that potentially integrates the labor market of other municipalities in the region. This study may illuminate new discussions about the recent urbanization processes in the state of Rio de Janeiro, mainly because it is a region demographically integrated, but politically fragmented.

Keywords: Population arrangements. Urban centrality. Rio de Janeiro.

\section{Resumen}

Movilidad circular e integración regional en el este de Río de Janeiro

La movilidad circular es una medida importante para evaluar los procesos de integración de las ciudades y la dinámica regional de la población. En 2015, el IBGE identificó una intensificación del movimiento de personas entre los municipios del este de Río de Janeiro, considerándolo un aspecto relevante de la urbanización brasileña. Sin embargo, se sabe poco sobre el peso de la movilidad entre estos municipios, el nivel de conexiones entre ellos y el nivel de interacción entre estos municipios y Macaé, el principal destino de quienes se movilizan circularmente en la región. Este trabajo analiza el grado de integración regional del vector fluminense oriental basado en los datos de los censos de 2000 y de 2010. La movilidad para el trabajo o el estudio observada en Macaé coloca al municipio en una posición prominente entre los municipios 
seleccionados. Por lo tanto, afirmamos que Macaé no es solo una ciudad en movimiento, sino un municipio que potencialmente integra el mercado laboral de otros municipios de la región. Es alrededor de este municipio que el tejido urbano regional se ha reorganizado. Este estudio puede iluminar nuevas discusiones sobre los recientes procesos de urbanización en el estado de Río de Janeiro, principalmente porque es una región demográficamente integrada, pero políticamente fragmentada.

Palabras clave: Arreglos de población. Centralidad urbana. Río de Janeiro.

Recebido para publicação em 10/07/2020

Aceito para publicação em 24/08/2020 